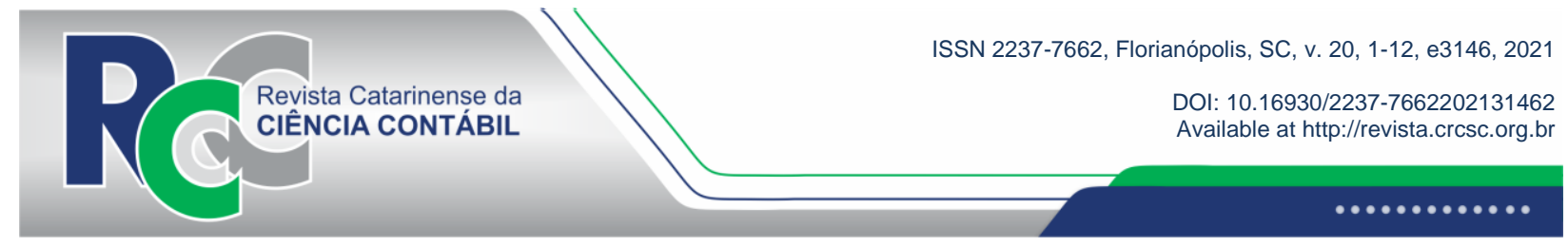

\title{
THE INFLUENCE OF THE GEOGRAPHICAL ENVIRONMENT ON ISLAMIC BANKING PERFORMANCE
}

\author{
AHMED SAMEER EL KHATIB \\ Centro Universitário FECAP \\ Address: Rua da Liberdade, 532| Liberdade | 01502-001 | \\ São Paulo, SP | Brazil. \\ (1) https://orcid.org/0000-0002-0764-8622 \\ ahmed.khatib@fecap.br
}

\begin{abstract}
The main goal of this study is to examine the influence of the geographic environment on the performance of Islamic banks present in four regions: Africa, Asia, Europe and North America. To achieve this goal, we have used daily data from 113 Islamic banks between 2010 and 2019. We applied different methodological approaches, such as principal component analysis and quantile regression with fixed effects for panel data. As a result, we found that the analysis of the main components shows that the performance of Islamic banks varies between regions. The regression of the linear panel highlights that the geographic environment positively and significantly affects the Islamic banking system, suggesting the importance of this aspect's effects. Finally, the environmental effect seems to vary with the quantiles, bringing positive effect to the lower quantile and negative effect to the highest quantile. This quantile specification points to the environment-performance nonlinear relationship of the Islamic bank, reflecting a discipline variable in the time imposed by the Council of Shariah or Islamic Law. This discovery helps to better explain the main difference between Islamic banks in the East and those in the West, and also allows investors to adjust their portfolio options when considering the products of Islamic banks according to regional specificities.
\end{abstract}

Keywords: Islamic Finance. Geographic Environment. Panel Data. Quantile Regression.

Edited in Portuguese and English. Original version in Portuguese.

Received on 1/8/2021. Reviewed on 3/29/2021. Accepted on 4/15/2021 by the Prof. PhD Sérgio Murilo Petri (Editor-Chief) and Prof. PhD Sandro Vieira Soares (Associated Editor). Published on 5/7/2021.

Copyright $\odot 2021$ RCCC. All Rights Reserved. It is allowed to quote part of articles without prior authorization, provided that the source is identified. 


\section{INTRODUCTION}

The central feature of Islamic Banks (IBs) is the prohibition on paying and receiving interest (or the Islamic term riba). The conventional definition of riba is the prohibition on charging interest on lending money and any unjustified additions (such as fines). Lending money at interest allows lenders to increase their capital effortlessly because money alone does not create added value. In addition, Islamic finance prohibits investment in transactions involving gambling, alcohol and drugs and transactions including uncertainty about the subject and terms of the contracts (or the Arabic word gharar). This practice includes a ban on selling something that is not owned by you or the characteristics of which are uncertain and under ambiguous contractual conditions. In Islamic finance, capital must have a social and ethical purpose in addition to pure and unrestricted return. In addition, the association between risk-return and the notion of profit and loss sharing and partnerships inherent in Islamic contracts are central to Islamic finance.

The Islamic Banking system was originally developed in the 1970s to protect the product of oil production in the Persian Gulf countries. However, it has rapidly increased in recent years not only in this region but also globally. While some countries have fully adopted the Islamic Banking system as the main banking system, in other countries the Islamic Banking system has been partially introduced in parallel with conventional banks. To illustrate this rapid growth in the Islamic Banking sector it is important to note that its assets totaled around US\$ 2 trillion in 2018. In addition, according to the World Islamic Banking Competitiveness Report [Ernst \& Young Global Limited (EY), 2020], the Islamic Banking sector has grown faster than the conventional or traditional banking sector at an annual rate of $17.6 \%$ between 2009 and 2018 and an average annual growth of $19.7 \%$ is expected until 2021. Thus, IBs are governed by a system that regulates and operates banking activities under the Islamic economy, consistent with the principles of the Shariah law (a religious law forming part of the Islamic tradition). Consequently, the Islamic Banking system is also called a Shariah-compliant system. Application of these religious rules aims to reduce risk-taking and create a more ethical and moral financial system (Lewis and Algaoud, 2001; Kabir, Worthington and Gupta, 2015).

While previous related studies tend to perform quantitative analyses, the main contribution of this study refers to the proposal of a hybrid analysis incorporating some qualitative dimensions to assess the IBs' financial performance. In this sense, this study answers the following question: Does the geographical environment affect the Islamic Banks' performance? The investigative hypothesis revolves around understanding whether the business associated with Islamic financial products in a Muslim country is different from that in a nonMuslim country. Banking businesses also vary between Muslim countries because they reach high levels when only IBs exist in one country while they are less significant in countries where conventional banks and IBs coexist. In addition, the Islamic Banking system shows different regional performances depending on the presence of an official financial/banking authority (Kabir, Worthington and Gupta, 2015; Jawadi, Jawadi, Ben Ameur and Idi Cheffou, 2017). The selection processes for eligible companies in relation to Shariah rules also vary at a regional level and by country. In addition, other factors such as lack of transparency, the IB's image and confusion between Islamic jurisprudence issues can differently affect IBs.

Therefore, the Islamic Banking system requires more investigation and research, given its rapid development in the past two decades in the Middle East as well as in Europe and the United States. In particular, it is important to specify IBs' performance factors to better inform investors and policy makers about their specificities, opportunities and global perspectives (Jawadi et al., 2017). Focus on performance is particularly important as it allows us to study return and financial risk, which are crucial for investors. Performance analysis is also necessary to improve the asset prices valuation and classification. On the other hand, regional performance 
research helps to specify precisely the regional factors that investors should take into account when investing in an Islamic Bank's products. Therefore, this study focuses on the IBs' performance while clarifying inconclusive conclusions and mixed results from previous literature on IBs and geographical environment. It is not the aim of this research to compare the Islamic Banking system with the conventional system. Instead, we have checked whether this findings heterogeneity is associated with the presence of different cultural, geographical and religious factors that can differently affect IBs.

This effect quantification is performed using a data specification in a nonlinear panel allowing to capture the environment effect by quantile. In addition, the use of panel dimensions and time allows us to model a more robust sample of data (Jawadi et al., 2017). In the context of an apparent lack of consensus in the literature on the Islamic Banking system growth, this study makes a valuable contribution in trying to model and capture the inherent nonlinearities in the IBs' performance in different geographical locations.

\section{LITERATURE REVIEW}

Due to the last global financial crisis (GFC) (2007-2008), conventional banks suffered large losses and IBs were considered capable of protecting investors from large losses in times of financial uncertainty. As such, the Islamic Banking system has become the subject of several empirical studies focusing on bank returns, risks and performance. However, these studies have not reached unanimous conclusions about the environment influence on the IBs' performance. On the one hand, they seem to improve a country's economic growth and macroeconomic efficiency (Imam and Kpodar, 2010; Gheeraert and Weill, 2015; Imam and Kpodar, 2016). It has been found that IBs are more efficient, with better performance and less risk when compared to conventional banks due to their adherence to a religious reference and ethical rules as well as the prohibition of excessive risk and speculation (Lewis and Algaoud, 2001). In addition, the recent effect of the last major global financial crisis appears to have been less costly for IBs than for conventional banks given the natural risk-averse characteristics of the IB products (Fakhfakh, Hachicha, Idi Cheou and Selmi, 2016). On the other hand, some studies show that IBs differ little from conventional banks, finding that the two types of banks are indirectly in competition (Jawadi, Cheffou and Jawadi, 2016b). In addition, IBs have been criticized for not being sufficiently ethical and transparent in providing a typical model with which to lead conventional banks (Imam and Kpodar, 2010; Jawadi, Cheffou and Jawadi, 2016a).

The rise of the Islamic Banking system on the global financial scene has quickly attracted academic attention and the list of journals that empirically evaluate the IBs' performance is expanding. The initial literature focuses mainly on measuring the IBs' efficiency. Then it evolved to identify the determinants of IBs' efficiency and later it extends to other metrics or measures of bank performance mainly evaluated in comparison with conventional banks (Hassan and Aliyu, 2018; Narayan and Phan, 2019). For example, Beck, Jonghe and Schepens (2013), Kabir and Worthington (2017), Zins and Weill (2017) and Ibrahim and Rizvi (2018) compare the risk and stability of Islamic and conventional banks. In the meantime, Olson and Zoubi (2017) and Yanikkaya, Gumus and Pabuccu (2018) comparatively examine the profitability of both types of banks. The IBs' efficiency in comparison with conventional banks is evaluated in the studies by Beck and Hesse (2009), Imam and Kpodar, 2010 and Abdul-Majid, Manizheh and Mansor (2017) and Alqahtani, Mayes and Brown (2017).

In practice, IBs' products seem, a priori, less risky than conventional banks due to the application of Shariah principles (for example, prohibition of speculation, prohibition of interest rates). However, this conclusion is questionable because most standard banks support only bank risk while IBs support standard bank risk and an additional specific risk associated with the Islamic financial contracts' characteristics. This adds more ambiguity when considering IBs. For 
all these reasons, the IBs' performance and efficiency levels remain uncertain despite the significant number of related empirical studies. In addition, these empirical studies results vary according to the sample data and the periods considered (Fakhfakh et al., 2016) and the number of countries analyzed (Jawadi et al., 2017).

Using bank details from 22 Muslim countries, Abedifar, Hasan e Tarazi (2016) verify the potential benefits of the presence of IBs in conventional banks in these countries. In other words, conventional banks operating in predominantly Muslim countries experience improvements in their cost efficiency when there are also large IBs operating in the same country. Arouri, Ben Ameur, Jawadi, Jawadi and Louhichi (2013) and Jawadi et al. (2017) provide more support for the influences of the presence of IBs on conventional banking behavior. More specifically, according to Arouri et al. (2017) and Jawadi et al. (2017) deposit rates for conventional banks tend to be higher and therefore benefit depositors in countries where there is a strong presence of IBs.

\section{METHODOLOGY}

We used daily data for the period from July 2010 to April 2019, obtained from Bloomberg. Data includes the closing price for the $113 \mathrm{IBs}$ established in four regions (Africa, Asia, Europe and the United States): International Bank of Kuwait, Egypt (IBKE); Faisal Islamic Bank in Egypt (FIBE); Al-Baraka, Egypt (ABE); Islamic Bank of Jordan (BIJ); Commercial Bank in Kuwait (CBK); Bank Muscat International in Bahrain (BMIB); Qatar International Bank (QIIBD); Al-Rajhi Bank in Saudi Arabia (ARBSA); Abu Dhabi Islamic Bank (BIAD); Islamic Bank of Dubai (DIB); European Islamic Bank in the United Kingdom (EIIBUK); and Albaraka Partners in the United States (APUSA). The sample is sufficiently heterogeneous and includes the main banks, which ensured the coverage of the main activities of these institutions around the world. However, the sample was limited due to data unavailability. Consequently, it was not possible to identify the same number of IBs per region. We also included the price of West Texas Intermediate (WTI) oil as a control variable. This allows us to verify the connection between oil prices and Islamic banks following studies by Jawadi et. (2017).

In addition, we used a proxy to measure the performance of the IBs. The proxy selection for performance was oriented according to data availability. Therefore, first of all, we used two proxies: Tobin Q and Return on Assets (ROA), and we run tests for both proxies. However, as the results were very close, we kept only those of Tobin's Q. Tobin's Q represents the ratio between the market value of an IB's existing shares and the replacement cost of its physical assets. The advantage of Tobin's Q is that it takes into account the interest rate and expected return (e.g., Lindenberg \& Ross, 1981; Hayashi, 1982; Skinner, 1993; Chung and Pruitt, 1994). Finally, to proxy the geographic environment variable, observed as Amb in the Equation (1), and measure its effect on the performance of the IBs, we created a dummy variable and defined the environment variable as follows:

$$
A m b_{t}=\left\{\begin{array}{c}
1 \text { se o IB estiver no Ocidente } \\
0 \text { caso contrário }
\end{array}\right]
$$

In other words, the environment variable assumes two values that vary depending on the location of the IB under consideration. It will be 1 if the bank is in the East (Africa and Asia) and 0 if the bank is in the West (Europe and the United States). In the first region, IBs are mainly in Muslim countries, while in the West, Islam is not the main religion and culture is also different from that of the East. Consequently, equation (1) allows capturing the effect of the variable environment in time and by region. Therefore, this choice indirectly captures the different dimensions (e.g., culture, religion, regulations and law, traditions of society, beliefs) that vary by 
region. This specification allows us to verify whether environmental heterogeneity affects the banks' financial performance.

Then, to obtain an overview of the performance among the 113 banks, we reported their main descriptive statistics in Table 1. These statistics were obtained using Tobin's Q. Table 1 shows that, for all IBs considered, the average Tobin Q is above 1, except for FIBE and EIIBUK banks. This indicates that additional investments in most banks would make sense, as the profits generated would exceed the cost of the bank's assets. We also found an important volatility excess for Tobin's Q in most IBs, particularly APUSA (16\%) and ARBSA (18\%), implying a significant variation in these banks' performance. This excess volatility can be justified by the fact that, during this period, the IBs returns were more variable due, perhaps, to the effect of the global financial crisis, liquidity crisis of conventional banks and economic slowdown. Apart from the DIB and APUSA banks, an important excess of kurtosis (leptokurtic) characterizes the distributions of the other banks. Finally, normality is strongly rejected for all series. The series under consideration also show positive asymmetry, indicating that the distribution is tilted to the right with a longer upper tail than a lower tail.

Table 1

Tobin's Q Descriptive Statistics

\begin{tabular}{lcccccccccccc}
\hline & IBKE & FIBE & ABE & JBI & CBK & BMIB & QIIBD & ARBSA & BIAD & DIB & EIIBUK & APUSA \\
\hline Sig. & 1.06 & 0.99 & 1.01 & 1.06 & 1.10 & 1.04 & 1.18 & 1.32 & 1.04 & 1.05 & 0.61 & 1.35 \\
Average & 1.02 & 0.98 & 1.00 & 1.05 & 1.06 & 1.02 & 1.16 & 1.28 & 1.02 & 1.02 & 0.60 & 1.36 \\
Max. & 1.34 & 1.14 & 1.09 & 1.15 & 1.46 & 1.33 & 1.71 & 2.21 & 1.19 & 1.27 & 0.96 & 1.76 \\
Min. & 0.97 & 0.97 & 0.98 & 1.02 & 1.02 & 0.97 & 1.11 & 1.13 & 0.99 & 0.96 & 0.51 & 0.98 \\
SD & 0.09 & 0.04 & 0.03 & 0.03 & 0.09 & 0.08 & 0.12 & 0.17 & 0.04 & 0.08 & 0.10 & 0.13 \\
Skew & 1.96 & 2.67 & 1.99 & 1.43 & 2.56 & 2.76 & 2.63 & 1.99 & 1.89 & 1.02 & 1.56 & 0.16 \\
Kurt & 6.68 & 9.76 & 5.93 & 5.90 & 9.03 & 10.14 & 9.27 & 9.25 & 6.69 & 3.45 & 5.84 & 3.77 \\
J-B & 0.00 & 0.00 & 0.00 & 0.00 & 0.00 & 0.00 & 0.00 & 0.00 & 0.00 & 0.00 & 0.00 & 0.00 \\
Obs. & 3,153 & 3,153 & 3,153 & 3,153 & 3,153 & 3,153 & 3,153 & 3,153 & 3,153 & 3,153 & 3,153 & 3,153 \\
\hline
\end{tabular}

Note. Obs indicates the number of observations.

Max and Min refer to the maximum and minimum Tobin's Q values, respectively.

Average, SD, Skew, Kurt denote the median value, standard deviation, asymmetry and kurtosis, respectively.

Next, we calculate the correlation matrix to provide an overview of other links between performance and investment of IBs. Table 2 shows the strong correlation between the IBs, considering the reasons for Tobin's Q. It is important to note that while the performance measure for IBs in the United States is less related to the performance measure, for other IBs there is more evidence of high regional links. For peers (IBKE, BIAD), (IBKE, ARBSA), (BIJ, BMIB), (BMIB, ARBSA) and (CBK, QIIBD), bilateral correlations exceed 60\% and reach $91 \%$ for the last pair. Overall, this indicates that, a priori, banks that evolve in similar regions share common cultural, social and environmental factors that indirectly affect their development and performance in the same way.

Table 2

\section{Correlation Matrix}

\begin{tabular}{lcccccccccccc}
\hline & IBKE & FIBE & ABE & BIJ & CBK & BMIB & QIIBD & ARBSA & BIAD & DIB & EIIBUK & APUSA \\
\hline IBKE & 1.00 & 0.11 & 0.66 & 0.71 & 0.81 & 0.82 & 0.75 & 0.86 & 0.20 & 0.41 & 0.55 & 0.02 \\
FIBE & & 1.00 & 0.23 & 0.31 & 0.28 & 0.20 & 0.27 & 0.05 & 0.22 & 0.37 & 0.13 & 0.22 \\
ABE & & & 1.00 & 0.66 & 0.80 & 0.73 & 0.87 & 0.52 & 0.37 & 0.55 & 0.75 & 0.33 \\
BIJ & & & & 1.00 & 0.80 & 0.60 & 0.84 & 0.48 & 0.36 & 0.70 & 0.40 & 0.16 \\
CBK & & & & & 1.00 & 0.90 & 0.91 & 0.72 & 0.51 & 0.77 & 0.75 & 0.37 \\
BMIB & & & & & & 1.00 & 0.81 & 0.86 & 0.39 & 0.58 & 0.73 & 0.39 \\
QIIBD & & & & & & & 1.00 & 0.66 & 0.47 & 0.68 & 0.71 & 0.27 \\
ARBSA & & & & & & & 1.00 & 0.11 & 0.25 & 0.51 & 0.09 \\
& & & & & & & & & & & & \\
\hline
\end{tabular}




\begin{tabular}{|c|c|c|c|c|}
\hline BIAD & 1.00 & 0.67 & 0.37 & 0.42 \\
\hline DIB & & 1.00 & 0.55 & 0.59 \\
\hline EIIBUK & & & 1.00 & 0.30 \\
\hline APUSA & & & & 1.00 \\
\hline
\end{tabular}

In a nutshell, this preliminary analysis suggests different designs for Islamic banks when considering geographic factors. This tool, however, assumes that the dataset is a linear combination of variables. Thus, we have extended this approach to directly test the effect of the geographic environment on IBs, considering various linear and nonlinear specifications to better capture the IB's performance dynamics and drivers.

\section{RESULTS ANALYSIS}

We shall first introduce the linear panel data specification used to assess the geographical environment effect on the IBs' performance. Secondly, we present the quantile regression approach to verify other asymmetric effects. It is estimated that both models investigate the IBs' performance dynamics among regions. Interestingly, it is necessary to use a panel data structure to consider more heterogeneity among IBs.

\subsection{Linear panel data specification}

We have investigated the geographical environment effect on the IBs' performance in a univariate linear structure. For this purpose, we have estimated the following fixed panel data model:

$$
Q T_{i, t}=\propto_{i, 0}+\beta \propto A m b_{i, t}+\varepsilon_{i, t}
$$

Where:

$\propto_{i, 0}$ and $\beta$ are regressor parameters,

$\varepsilon_{i, t} \quad \rightarrow$ i.i.d. $\left(0, \sigma^{2}\right), \forall t=1, \ldots$, T e $i=1, \ldots . ., N Q T$ denotes Tobin's Q,

$A m b$ defines the environment variable,

$\mathrm{N}$ indicates the number of Islamic Banks (IBs).

We have estimated Equation 2 and reported the main results in Table 3. These results show that the geographical environment significantly and positively affects the IBs' performance and therefore the development. This result suggests that IBs in the East do not benefit from natural and positive externalities compared to IBs in the West.

Regression 2 aims to assess the environment effects. A control variable associated with oil returns is added to extend regression 2 to verify the results validity of this. Below we call this extended regression model 3. Interestingly, model 3 validates our previous findings. In fact, the model 2 results remain robust even when we estimate model 3 . Regarding the effect of oil, model 3 shows that this is positive and significant, suggesting a positive reaction from the oil industry to the IBs' activities. Although this finding confirms that IBs have emerged to protect the resources of the oil market, the effect of oil is nevertheless low (below 4\%). This is explained by the fact that, during the period considered in this study, oil prices increased and oil benefits decreased. Even when considering other proxies for oil prices, the results remain unchanged. In addition, to verify the robustness of our specification we found that regression 2 aims to assess the environment effects. A control variable associated with oil returns is added to extend the collinearity of regression 2 among the explanatory variables, again using the ACP. Our results show that the first eigenvalues are statistically different from zero, suggesting a weak condition index and therefore the absence of collinearity. 
Table 3

\section{Linear panel data regression estimation}

\begin{tabular}{lcc}
\hline Coefficients & Model 2 & Model 3 \\
\hline Constant & $-0.32^{* * *}$ & $-0.47^{* * *}$ \\
& $(0.00)$ & $(0.00)$ \\
& $0.44^{* * *}$ & $0.43^{* * *}$ \\
& $(0.00)$ & $(0.00)$ \\
& - & $0.03^{* * *}$ \\
R2 & - & $(0.00)$ \\
LL & 0.59 & 0.61 \\
Prob. (F - Test) & $10,057.64$ & $10,105.34$ \\
\hline
\end{tabular}

Note. $\mathrm{R}^{2}$ and LL denote the adjusted square $\mathrm{R}$ and the logarithmic probability and respectively values in (.) refer to robust p-values. (***) indicates significance at the $1 \%$ level.

Test $\mathrm{F}$ indicates the Fisher's test.

Although this conclusion implies a positive and significant effect of the geographical environment on the IBs' financial performance, the structure under consideration only captures the linear effect around the average. The structure cannot reproduce the environmental effect when the prices of IB products are subject to high volatility and significant changes. Hence, we have extended model (3) and focused on the quantile regression, which was introduced by Koenker and Bassett (1978) and developed by Koenker and Hallock (2001) and Koenker (2005). This has the advantage of considering a greater asymmetry and calculating the environmental effect around different ones. As the IBs' environmental standards (Shariah rules, criteria for ethical selection, the IBs' reputation and consideration, cultural aspects, analysis of the IBs' products) evolve over time as well as the IBs' financial performance and size, the geographical environment effect may follow a nonlinear pattern that can escape linear modeling. Thus, we have adopted a quantile regression to analyze the relationship between the IBs' environment and performance. In particular, the environmental effect may vary over time. In fact, the environmental norms presented can show discomfort that affect the IBs' activity in a different and temporal fashion. For example, the effect can vary with the business cycle phase (crisis versus a tranquil period) and be asymmetrical. In addition, any mutation or news that reaches the market can affect society and its environment. In order to adequately explain these changes in environmental effects, an accessible econometric structure, such as the quantile regression model, becomes necessary.

\subsection{The Quantile Regression (QR) specification}

Here we have tested whether the environmental impact on the Islamic Banking sector is stronger (or weaker) when the IBs' performance is extraordinarily high (or low). Finally, we have specified a linear panel quantile regression as follows:

$$
q_{\propto}\left(Q T_{i, t} \mid \Omega_{t}\right)=\text { constante }+\Phi_{1, \alpha} A m b_{i, t}+\Phi_{2, \alpha} R o_{i, t}
$$

Where:

$\Omega_{t}$ denotes all information available at time t,

$\Phi_{1, \alpha}$ and $\Phi_{2, \alpha}$, are the slope coefficients that vary by quantile, $q_{\propto}\left(Q T_{i, t} \mid \Omega_{t}\right)$ defines the conditional quantile.

Thus, Equation (3) assesses the environmental effect when estimating the distribution of the IBs' performance. Technically, the parameters of the quantile forecasting model are 
estimated by replacing the quadratic loss function with the following loss of scale function:

$$
L \propto\left(e_{i, t}+1\right)=\left(\propto-1\left\{e_{i, t}+1<0\right\}\right) e_{i, t}+1
$$

Where:

$e_{i, t}=Q T_{i, t}-q_{\alpha, i, t}$ denotes the forecast error

$q_{\alpha, i, t}=q_{\alpha}\left(Q T_{i, t} \mid \Omega_{t}\right)$ is the conditional quantile prediction at time $\mathrm{t} 1\left\{e_{i, t}+1<0\right\}$ is an indicator function

As in Jawadi and Sousa (2014), confidence intervals are calculated using an inversion of a classification test. Consequently, the first order condition associated with the minimization of the expected value of (4) in relation to the forecasts, $q_{\alpha, i, t}$ corresponds to the quantile of Tobin's $\mathrm{Q}$ distribution. Koenker (2005) shows that the ideal forecast is the conditional quantile, $q_{\alpha, i, t}=$ $F^{-1}(\alpha)$, where $\mathrm{F}_{\mathrm{t}}$ is the conditional distribution function of Tobin's $\mathrm{Q}$. We have estimated Equation (3) for different quantiles and reported in Table 4 the main results associated with the effect of the geographic environment per quantile.

Table 4 provides some interesting results. First, when the IBs' performance is close to the median, the effect of the geographic environment, although positive, is close to zero. Second, the environmental effect is particularly different when the distribution of the IB's performance is close to the tails of the distribution. We have observed a large coefficient when the IBs' performance is close to the $2.5 \%$ and $25 \%$ quantiles. The coefficients for these two quantiles $(0.65$ and 0.50$)$ are greater than the coefficients of the OLS estimate $(0.43)$. However, when the IBs' performance is close to the $75 \%$ and $97.5 \%$ quantiles, the environmental effects are negative.

Table 4

\section{Quantile regression estimation}

\begin{tabular}{lc}
\hline Quantile & Environmental Effect $(\Phi)$, \\
\hline $2.5 \%$ & $0.65 * * *$ \\
$25 \%$ & $0.50^{* * *}$ \\
$50 \%$ & $0.06 * * *$ \\
$75 \%$ & $-0.21^{* * *}$ \\
$97.5 \%$ & $-0.16^{* * *}$ \\
OLS & $0.43^{* * *}$ \\
Wald Test (p-value) & $0.00^{* * *}$ \\
Koenker and Xia (2006) Test (p-value) & $0.00^{* * *}$ \\
\hline
\end{tabular}

Note. $(* * *)$ significance at the $1 \%$ level. OLS denotes the model (3) estimate

Thus, these findings also confirm the nonlinearity inherent in the geographical environment effect on Islamic Banks. Thus, we conclude that the geographical environment effect on the IBs' performance is negative on the right tail of the distribution of the IBs' performance while it is positive on the left tail. This is explained by the fact that, for low levels of performance, the environment would stimulate and promote IBs' activities. However, when IBs achieve a high level of performance, Shariah's board intensifies control and activates rules to prevent IBs from pursuing business goals. Furthermore, this implies that, at the lowest point of the tail of the distribution, the geographical environment is positively correlated with the IBs' performance, while at the highest point of the tail the environment effect is negative.

Although these results point only to the significant environment effects on the IBs' performance when considering quantiles, we have applied two tests: the Wald test (test for 
equality of the quantile slope) and the Koenker and Xiao test (2006), which also calculates a joint test to verify that all co-variable effects satisfy the null hypothesis of equality of the slope coefficients among countries. Both tests significantly reject the null hypothesis, suggesting that the environment effect on the IBs' performances varies with the quantiles. Consequently, these results suggest the presence of variation in time in the environmental effect on the IBs' performance and imply that the relation of environmental performance versus IBs shows asymmetry and not linearity.

In other words, it appears that the control by Shariah's council authorities varies depending on the level of IBs' performance, generating time-varying discipline to control the IBs. In fact, when the IB makes a small return and shows poor performance, Shariah's board control action is not activated. On the contrary, for a high level of performance, Shariah can be more aggressive and strongly recall the moral, ethical, spiritual and social dimensions that an IB must show to pressure it to reduce its investment and keep Shariah in compliance with projects to a minimum. This action may justify the negative effect of the environment on the IBs' performance on the left tail. In addition, the fact that the level of this discipline and the application of Shariah's rules vary from country to country may justify the asymmetry and nonlinearity inherent in the banks' performance and environment relationship. This asymmetry can also be explained by the presence of different Islamic Banking schools or scholars, who do not always provide unanimous opinions for IBs' products and companies, generating different ways to invest in IBs.

In general, this finding suggests greater nonlinearity and asymmetry in the relationship between the IBs' performance and the geographical environment. The results confirm that the IBs' performance significantly varies among regions. However, as shown by Canay (2011) and Jawadi et al., 2017 when considering data from the quantile regression panel, the consistency of the estimators can be important. Indeed, Canay (2011) provides a set of conditions sufficient to identify a quantile regression model with fixed effects. The author shows that, as $\mathrm{n}$ (the number of people) and $\mathrm{T}$ (increased period), the estimator obtained is consistent and asymptotically normal. In our study, the data are daily and the period is high enough but the number of banks is relatively small $(n=113)$. Therefore, the estimator consistency must be analyzed with caution. However, it is important to note that this quantile regression surpasses the linear model, as it provides a more apparent quantile analysis, less sensitive to discrepancies and elongated distributions.

\section{FINAL CONSIDERATIONS}

This study has investigated the geographical environment effect on the IBs' performance. Our sample comprised 113 banks present in four regions (Africa, Asia, Europe and the United States) during the years 2010 to 2019 . As conclusions, we had that, first, a preliminary analysis of time series showed evidence of heterogeneity in these IBs' financial performance. Second, the ACP confirmed this heterogeneity and showed that IBs in the East differ from IBs in the West. Then we evaluated the direct effect of the geographical environment on IBs' performance using a linear regression of panel data and quantile regression. While the linear regression pointed to a positive and significant effect, the quantile regression showed that the environmental effect varies with the quantiles, suggesting more evidence of asymmetry and nonlinearity. The environmental effect is positive (negative) and significant for the lowest (highest) tail distribution of the IBs' performance. This is an indication of asymmetry, nonlinearity and complexity in the relationship between IBs and the geographical environment.

These findings have two important economic and political implications. First, our results help investors to identify the best performing IBs in each region. Second, our results clarify the effects of the geographical environment on the IBs' activities and help scholars to specify these 
externalities. In addition, while these results allow investors to improve their portfolios, including IBs' products, based on the region under consideration, our conclusion is useful to take into account the effects of these externalities to improve the Islamic Banking system.

To summarize, this study has focused on the performance-environment relationship for IBs. Therefore, we have not included conventional banks but they can be included in future models. It has shown that the geographical environment affects IBs and quantifies this effect but it has not identified its components (culture, religion, law, regulations), which can be an additional extension. In addition, our results do not imply that IBs in the West (Europe and the United States) are not promising but that the IBs' performance may vary by region according to their location and environment. An additional future extension would be to see what factors drive this environmental effect. To do this, quantitative and qualitative data on culture, religion, regulation and business would be needed for a large sample of IBs in different regions of the world. In addition, looking at the underlying variation in eastern IBs is also an interesting research topic that can allow us to identify whether cultural/environmental differences between IBs in the East and in the West can boost the IBs' performance.

\section{REFERENCES}

Abedifar, P., Hasan, I., \& Tarazi, A. (2016). Finance-growth nexus and dual-banking systems: Relative importance of Islamic banks. Journal of Economic, Behavior \& Organization, 132 (3), 198-215.

Abdul-Majid, M., Manizheh, F., \& Mansor, J. (2017). Performance of Islamic and conventional banks: A meta-frontier approach. Research in International Business and Finance, 42(3), 1327-1335.

Alqahtani, F., Mayes, D. G., \& Brown, K. (2017). Islamic Bank Efficiency Compared to Conventional Banks During the Global Crisis in the GCC Region. Journal of International Financial Markets, Institutions and Money, 51, 58-74.

Arouri, M., Ben Ameur, H., Jawadi, N., Jawadi, F., \& Louhichi, W. (2013). Are Islamic performance innovations enough for investors to escape from a financial downturn? Further evidence from portfolio simulations. Applied Economics, 45(24), 3412-3420.

Beck, T., De Jonghe, O., \& Schepens, G. (2013). Bank Competition and Stability: Cross-Country Heterogeneity. Journal of Financial Intermediation, 22, 218-244.

Beck, T., \& Hesse, H. (2009). Why Are Spreads so High in Uganda? Journal of Development Economics, 88, 192-204.

Canay, I. A. (2011). A simple approach to quantile regression for panel data. The Econometrics Journal, 14(3), 368-386.

Chung, K. H., \& Pruitt, S. W. (1994). A simple approximation of Tobin's q. Financial management, 70-74.

Ernst \& Young (EY) (2020). World Islamic Banking Competitiveness Report 2019-20. Recuperado em 12 abril, 2020, de http://www.ey.com/Publication/vwLUAssets/ey-worldislamic-banking-competitiveness-report-2020/\%24FILE/ey-world-islamic-bankingcompetitiveness-report-2020.pdf 
Fakhfakh, M., Hachicha, N., Idi Cheou, A., \& Selmi, N. (2016). Measuring volatility persistence for conventional and Islamic banks: A FI-EGARCH approach. Emerging Markets Review, 27, 84-99.

Gheeraert, L., \& Weill, L. (2015). Does Islamic banking development favor macroeconomic e $\varnothing$ ciency? Evidence on the Islamic finance-growth nexus. Economic Modelling, 47, 32-39.

Hassan, M. K., \& Aliyu, S. (2018). A Contemporary Survey of Islamic Banking Literature. Journal of Financial Stability, 34, 12-43.

Hayashi F. (1982). Tobin's marginal Q and average Q: A neoclassical interpretation. Econometrica, 50, 213-224.

Ibrahim, M. H., \& Rizvi, S. A. R. (2017). Do We Need Bigger Islamic Banks? An Assessment of Bank Stability. Journal of Multinational Finance Management, 40, 77-91.

Ibrahim, M. H., \& Rizvi, S. A. R. (2018). Bank Lending, Deposits and Risk-Taking in Times of Crisis: A Panel Analysis of Islamic and Conventional Banks. Emerging Markets Review, 35, 31-47.

Imam, P., \& Kpodar, K. (2010). Islamic banking: How has it spread? International Monetary Fund, Working Paper.

Imam, P., \& Kpodar, K. (2016). Islamic banking: Good for growth? Economic Modelling, 59, $387-401$.

Jawadi, F., Cheffou, A., \& Jawadi, N. (2016a). Can the Islamic bank be an emerging leader? A panel data causality analysis. Applied Economics Letters, 23(14), 991-994.

Jawadi, F., Cheffou, A. I., \& Jawadi, N. (2016b). Do Islamic and conventional banks really differ? A panel data statistical analysis. Open Economies Review, 27(2), 293-302.

Jawadi, F., Jawadi, N., Ben Ameur, H., \& Idi Cheffou, A. (2017). Does Islamic banking performance vary across regions? A new puzzle. Applied Economics Letters, 24(8), 567-570.

Jawadi, F., \& Sousa, R. M. (2014). The relationship between consumption and wealth: A quantile regression approach. Revue D'économie Politique, 124(4), 639-652.

Kabir, M. N., \& Worthington, A. C. (2017). The 'Competition-Stability/Fragility' Nexus: A Comparative Analysis of Islamic and Conventional Banks. International Review of Financial Analysis, 50, 111-128.

Kabir, M. N., Worthington, A., \& Gupta, R. (2015). Comparative Credit Risk in Islamic and Conventional Bank. Pacific-Basin Finance Journal, 34, 327-353.

Koenker, R. \& Xiao, Z. (2006) Quantile Autoregression. Journal of the American Statistical 
Association, 101(2), 980-1006.

Koenker, R. (2005). Quantile Regression. Econometric Society Monograph Series, Cambridge University Press, Cambridge.

Koenker, R., \& Hallock, K. F. (2001). Quantile regression. Journal of economic perspectives, 15(4), 143-156.

Koenker, R., \& Bassett, G.S. (1978). Regression quantiles. Econometrica, 46, 33-50.

Lewis, M.K.L., \& Algaoud, L.M. (2001). Islamic Banking. Edward Elgar Publishing, Cheltenham, UK.

Lindenberg, E. B., \& Ross, S. A. (1981). Tobin's q ratio and industrial organization. Journal of Business, 1-32.

Narayan, P. K., \& Phan, D. H. B. (2019). A survey of Islamic banking and finance literature: issues, challenges and future directions. Pacific-Basin Finance Journal, 53, 484-496.

Olson, D., \& Zoubi, T. (2017). Convergence in Bank Performance for Commercial and Islamic Banks During and After the Global Financial Crisis. The Quarterly Review of Economics and Finance, 66, 71-87.

Skinner, D. J. (1993). The investment opportunity set and accounting procedure choice: Preliminary evidence. Journal of accounting and economics, 16(4), 407-445.

Yanikkaya, H., Gumus, N., \& Pabuccu, Y. U. (2018). How Profitability Differs Between Conventional and Islamic banks: A Dynamic Panel Data Approach. Pacific-Basin Finance Journal, 48, 99-111.

Zantioti, L. E. (2009). Does Islamic bank performance dier by region? PhD Thesis, Stockholm School of Economics.

Zins, A., \& Weill, L. (2017). Islamic Ranking and Risk: The Impact of Basel II. Economic Modelling, 64, 626-637. 